\title{
Article \\ Study on SPF/DB Technology for Two-Sheet Hollow Structure of 1420 Al-Li Alloy
}

\author{
Yaoming Li ${ }^{1}$, Honglin Wang ${ }^{2}$, Tao Niu ${ }^{3, *}$, Huang Zhang ${ }^{1}$ and Meini Yuan ${ }^{2, *}$ (i) \\ 1 School of Mechanical Engineering, North University of China, Taiyuan 030051, China; lym@nuc.edu.cn (Y.L.); \\ zhanghuang@nuc.edu.cn (H.Z.) \\ 2 College of Mechatronic Engineering, North University of China, Taiyuan 030051, China; \\ s2001108@st.nuc.edu.cn \\ 3 Aeronautical Key Laboratory for Plastic Forming Technology, Beijing 100024, China \\ * Correspondence: niut001@avic.com (T.N.); mnyuan@nuc.edu.cn (M.Y.)
}

Citation: Li, Y.; Wang, H.; Niu, T.; Zhang, H.; Yuan, M. Study on SPF/DB Technology for Two-Sheet Hollow Structure of 1420 Al-Li Alloy. Metals 2022, 12, 389. https://doi.org/ $10.3390 / \operatorname{met} 12030389$

Academic Editor: Hardy Mohrbacher

Received: 27 January 2022

Accepted: 21 February 2022

Published: 23 February 2022

Publisher's Note: MDPI stays neutral with regard to jurisdictional claims in published maps and institutional affiliations.

Copyright: (c) 2022 by the authors. Licensee MDPI, Basel, Switzerland. This article is an open access article distributed under the terms and conditions of the Creative Commons Attribution (CC BY) license (https:// creativecommons.org/licenses/by/ $4.0 /)$.

\begin{abstract}
The two-sheet hollow structure of the 1420 Al-Li alloy was prepared by the method of superplastic forming and diffusion bonding. The interface combination status of the diffusion bonding region and the microstructure of the superplastic forming region were observed by an optical microscope. The thickness distribution of the superplastic forming region was measured by an ultrasonic thickness meter machine, the defect detection was tested by X-ray nondestructive inspection, and the failure modes of the samples were analyzed. The results showed that the two-sheet hollow structure of the 1420 Al-Li alloy was prepared successfully, the structure was integrated, and there were no shape defects such as pit, wrinkle, and collapse. The structure shape was almost attached to the die completely, and the thickness was almost uniform distribution. The no deforming area of the two-sheet hollow structure of the 1420 Al-Li alloy was a long strip, rolled microstructure, while the grains near the round corner area were equiaxed states resulting from dynamic recrystallization. The improper control of the superplastic gas pressure in the forming process would lead to the tearing or the die-attaching failure for the two-sheet hollow structure of the 1420 Al-Li alloy.
\end{abstract}

Keywords: Al-Li alloy; hollow structure; superplastic forming; diffusion bonding

\section{Introduction}

As an advanced light alloy, Al-Li alloys have a series of advantages, such as low density, high modulus, high specific strength, high specific stiffness, good corrosion resistance, and superplasticity [1-4]. Due to these advantages, the Al-Li alloys have great application prospects in modern aircraft and aerospace vehicles. The weight of aircraft components made of Al-Li alloys can be reduced by 10 15\% compared with that made of conventional aluminum alloys. The $1420 \mathrm{Al}-\mathrm{Li}$ alloy is the lightest (density $2.47 \mathrm{~g} / \mathrm{cm}^{3}$ ) weldable corrosion-resistant alloy with a high elastic modulus and a strong superplastic forming ability. The 1420 Al-Li alloy is the most mature and widely used Al-Li alloy in the aerospace industry. Some 1420 alloy components have been used on the shell of MiG-29, Su-27, Su-35, and some medium- and long-range missile warheads. It is noted that the cost of Al-Li alloys is higher than that of ordinary aluminum alloys, and the formation of Al-Li alloys is difficult due to their poor plasticity at room temperature, high yield ratio, obvious anisotropy, and easy cracking during cold working. Superplastic forming and diffusion bonding (SPF/DB) is an advanced process technology with low cost, high effectiveness, and low requirement of machining allowance [5-8]. The SPF/DB technology has been widely used in aviation and space flight components, including aircraft engine blade, aircraft door, missile rudder wing surface, and aircraft ventral fins. During the production process of the multilayer hollow structure of Al-Li alloys using SPF/DB technology, the surface oxide film on Al-Li alloys is difficult to decompose and dissolve in the diffusion bonding process, 
which results in poor bonding quality. Shirzadi et al. [9-13] first proposed a method of taking Ga as the intermediate layer in aluminum alloys' diffusion bonding, and applied for a patent for invention. In this method, the aluminum alloy sample was polished in a disc coated with liquid $\mathrm{Ga}$, and Ga was evenly coated on the surface of the aluminum alloy specimen. In the process of diffusion bonding, the surface oxide film can be effectively restrained. Ferchaud et al. [14] also obtained a good diffusion bonding result using a similar method, and performed in-depth research on the surface activation mechanism of the aluminum alloy induced by Ga. In our previous works [15-17], the research of taking $\mathrm{Ga}$ as an intermediate layer in the 1420 Al-Li alloy's diffusion bonding has been deeply studied. Reasonable process parameters have been determined, such as the thickness of the intermediate layer $\left(1 \mathrm{mg} / \mathrm{cm}^{2}\right)$, temperature (slightly higher than $520^{\circ} \mathrm{C}$ ), pressure (higher than $7 \mathrm{MPa}$ ), and time (more than $1 \mathrm{~h}$ ). Bonded in these process conditions, the bonding interface almost disappeared, and the joint shear strength was more than $80 \mathrm{MPa}$.

Based on the previous research in diffusion bonding, this article reports the SPF/DB process of the $1420 \mathrm{Al}-\mathrm{Li}$ alloy hollow structure, and studies the superplastic forming quality (the thickness distribution) and the superplastic forming failure modes.

\section{Materials and Methods}

The sheet of $1420 \mathrm{Al}-\mathrm{Li}$ alloy with super plasticity was selected as the experimental material, which was prepared by Central South University. The sheet of 1420 Al-Li alloy was produced by thermo-mechanical processing, with the following preparation process: solution treatment at $475{ }^{\circ} \mathrm{C}$ for $2 \mathrm{~h}$, aging at $320{ }^{\circ} \mathrm{C}$ for $40 \mathrm{~h}$, preheating at $400{ }^{\circ} \mathrm{C}$ for $15 \mathrm{~h}$, and cross-rolling with a large reduction of $80 \%$. The thickness of the sheet was $1.5 \mathrm{~mm}$, and the chemical composition is shown in Table 1. Its microstructure presented typical fibrous tissue, and some fine grains were observed at the grain boundary of fibrous grains, as shown in Figure 1. This was because under the action of a large rolling force, some fibrous grains were broken and formed fine new grains. Gallium with a purity of $99.9999 \%$ was selected as an intermediate layer with a thickness of $1 \mathrm{mg} / \mathrm{cm}^{2}$. The surface of the Al-Li alloy easily forms a dense and stable oxide film at room temperature, and the oxide film does not decompose or dissolve in the Al-Li alloy during diffusion bonding, which seriously hinders the mutual diffusion of aluminum atoms. Liquid gallium can effectively destroy the oxide film on the surface of the $1420 \mathrm{Al}-\mathrm{Li}$ alloy and improve the surface activation. Therefore, the gallium intermediate layer was used for the diffusion of the 1420 Al-Li alloy.

Table 1. Chemical composition of the 1420 Al-Li alloy (wt.\%).

\begin{tabular}{ccccccccc}
\hline $\mathbf{L i}$ & $\mathbf{M g}$ & $\mathbf{Z r}$ & $\mathbf{F e}$ & $\mathbf{S i}$ & $\mathbf{T i}$ & $\mathbf{C u}$ & $\mathrm{Al}$ \\
\hline 2.0 & 5.2 & 0.12 & 0.07 & 0.03 & $\leq 0.1$ & 0.03 & $\mathrm{Bal}$ \\
\hline
\end{tabular}

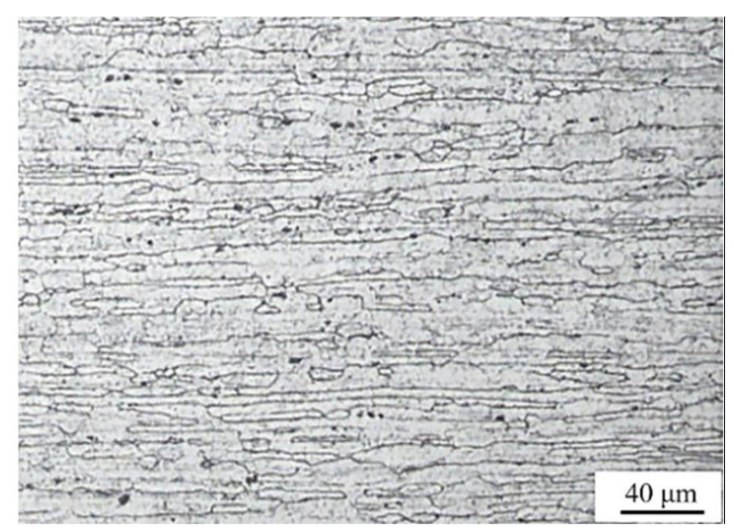

Figure 1. Microstructure of the 1420 Al-Li alloy. 
The shear strength of the diffusion bonding joint was measured on the universal testing machine(UTM4000, SUNS, Guangdong, China) (the sample size is shown in Figure 2), and the moving speed of the sample holder was $2 \mathrm{~mm} / \mathrm{min}$. The shear fracture morphology of the joint was observed and analyzed by the LEO-1450 scanning electron microscope (Angstrom Scientific, Inc., Ramsey, NJ, USA).
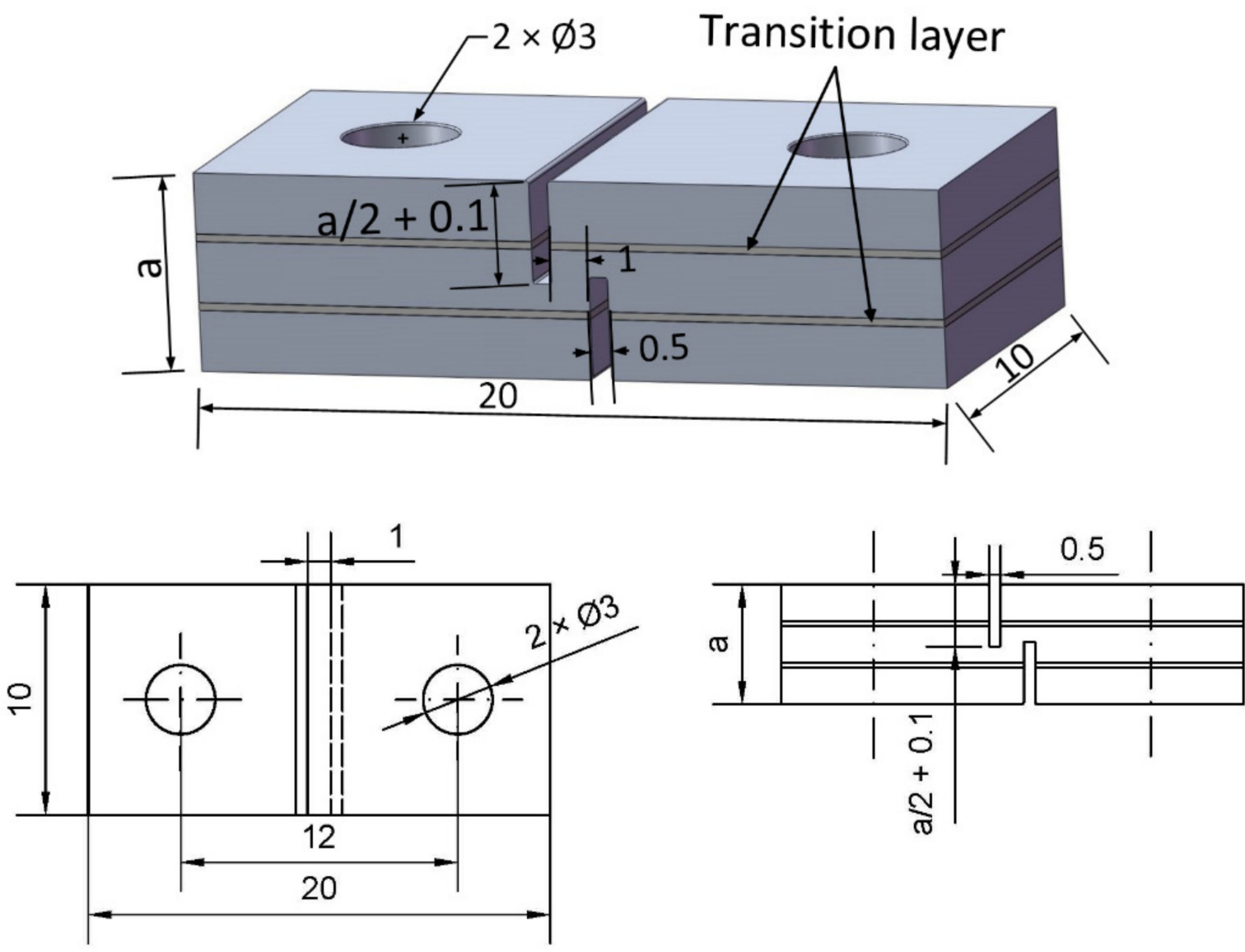

Figure 2. The specimen of the shearing test (units: $\mathrm{mm}$ ).

Manufacturing the two-layer hollow structure of the 1420 Al-Li alloy consists of (i) SPF and (ii) DB, and was developed on the $60 \mathrm{~T}$ SPF/DB special equipment(MOV HP, Pufa Top Vacuum Equipment (Beijing) Co. Ltd, Beijing, China). Figure 3 shows the preparation process of the two-layer hollow structure of the $1420 \mathrm{Al}-\mathrm{Li}$ alloy. The sample sheets with a size of $150 \mathrm{~mm} \times 310 \mathrm{~mm} \times 1.3 \mathrm{~mm}$ were prepared by the wire-cutting process. Grinding and polishing processes were used to ensure the sample surface roughness $\delta<3.2$. A cold paste machine (ZJYP-20T, Shanghai Xinnuo Instrument Group Co. Ltd, Shanghai, China) was used to coat the film on the sample surface. The plastic coating film was etched by a laser etching machine(Wuhan Hero Optoelectronics Technology Co. Ltd, Wuhan, China), and the etching track is shown in Figure 4. Gallium and de-flux were coated in the areas of diffusion and superplastic forming, respectively. Then, two pieces of the prepared sheets were stacked together and welded along the edges sing argon arc welding technology(ORION 250S, Sunstone, Payson, UT, USA). The aluminum alloy pneumatic pipe and pipe joint were welded at the position of the air inlets, as shown in Figure 4. The pneumatic pipe and the space of the sample sheets were highly evacuated, and then assembled in the molds which connected with the machine of diffusion bonding/superplastic forming (MOV HP, Pufa Top Vacuum Equipment (Beijing) Co. Ltd, Beijing, China). Niu et al. [17] reported that the diffusion bonding joint of the $1420 \mathrm{Al}-\mathrm{Li}$ alloy using gallium as the interlayer had good metallurgical bonding, and its interface shear strength reached $81.6 \mathrm{MPa}$ when the diffusion bonding temperature was $520{ }^{\circ} \mathrm{C}$, the 
pressure was $7 \mathrm{MPa}$, and the holding time was $1 \mathrm{~h}$. For the $1420 \mathrm{Al}-\mathrm{Li}$ alloy, its superplastic property increased with the decrease of the strain rate. The superplastic deformation mechanism of the 1420 Al-Li alloy is mainly grain boundary sliding, accompanied by dislocation movement and dynamic recrystallization. When the superplastic forming temperature was selected as $480{ }^{\circ} \mathrm{C}$ and the strain rate was $3 \times 10^{-4} \mathrm{~s}^{-1}$, the elongation of the $1420 \mathrm{Al}-\mathrm{Li}$ alloy was 550\% and the deformation was uniform [18]. Therefore, the corresponding preparation processing was adopted. When the temperature of the samples rose to $520^{\circ} \mathrm{C}$, a diffusion loading of $7 \mathrm{MPa}$, maintained for $1 \mathrm{~h}$, was applied to the samples. Then, when the temperature of the samples dropped to $480{ }^{\circ} \mathrm{C}$, argon was blown into the superplastic forming area through a pneumatic pipe to control the forming pressure and realize the superplastic forming of the sheets. Argon increased to $2 \mathrm{MPa}$ at the rate of $0.1 \mathrm{MPa} / \mathrm{min}$ for $20 \mathrm{~min}$, and was then maintained for $30 \mathrm{~min}$, as shown in Figure 5 . In other words, a superplastic forming load of $2 \mathrm{MPa}$ was applied to the samples. The formed components were removed from the molds after cooling to room temperature. The chemical milling and polishing processes were used to improve the formed components' surface. The wire-cutting process was used to remove the unwanted parts of edges, and then the hollow structure was obtained. The whole preparation process is shown in Figure 3. An optical microscope (Axioscope 5, ZEISS, Oberkochen, Germany) was used to observe the interface of diffusion bonding and the microstructure of the superplastic forming area. An ultrasonic thickness meter (TT130, Tianjin ZBL instrument sales Co. Ltd, Tianjin, China) was used to measure the thickness distribution of the superplastic forming area. X-ray nondestructive flaw detection(UNC450, Wuxi Unicomp Technology Co. Ltd, Jiangsu, China) technology was used to analyze the internal defects of the formed components.
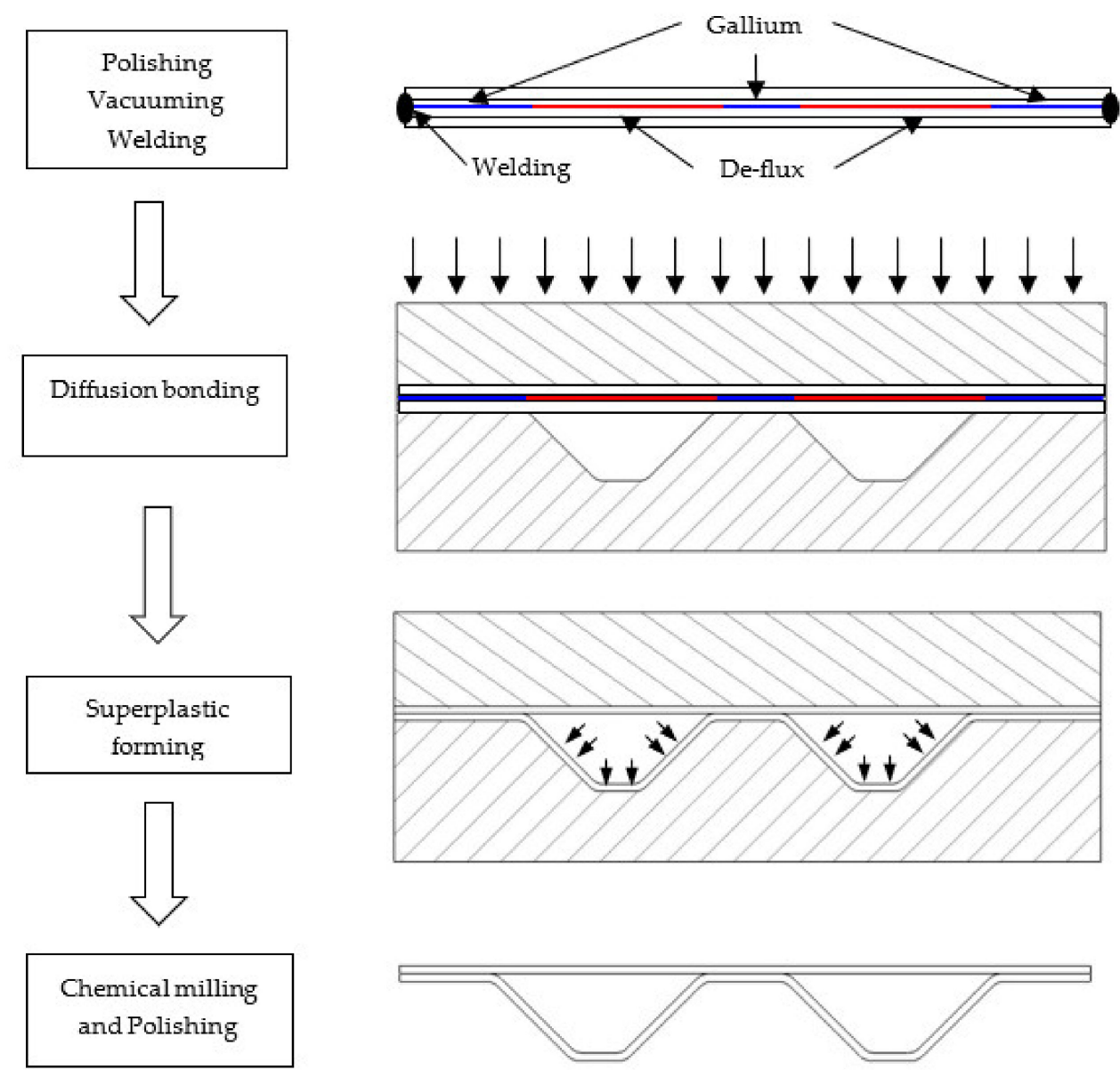

Figure 3. Preparation process of the two-layer hollow structure of the 1420 Al-Li alloy. 


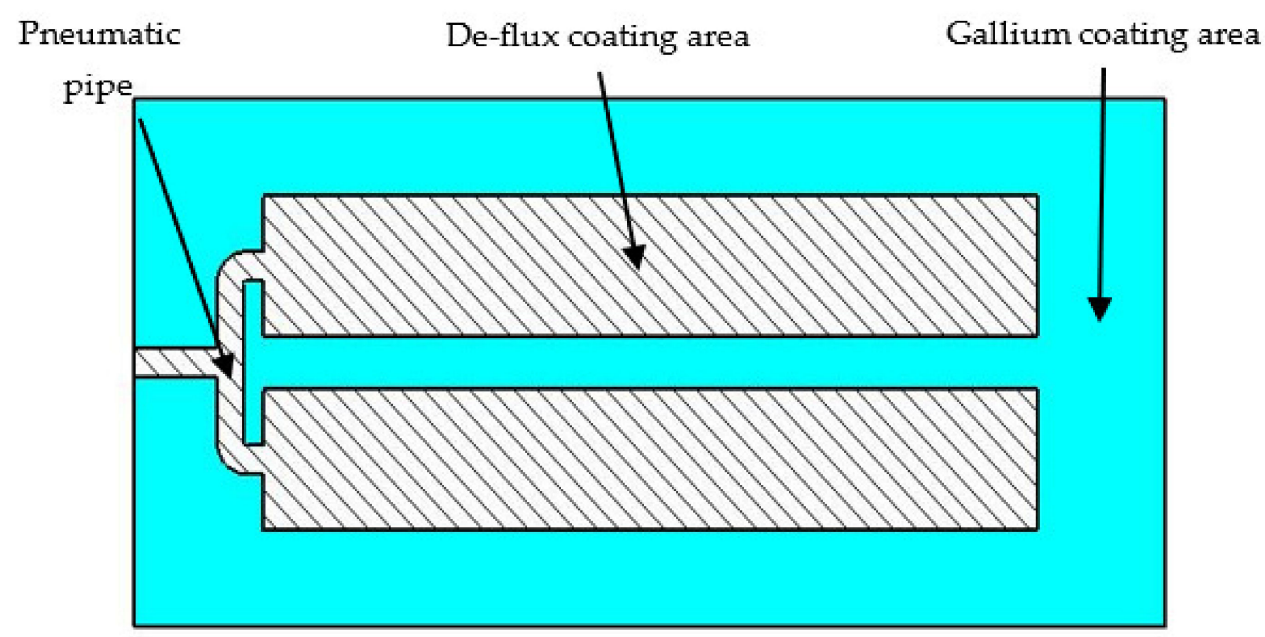

Figure 4. Area of Ga coating and de-flux coating on the sample surface.

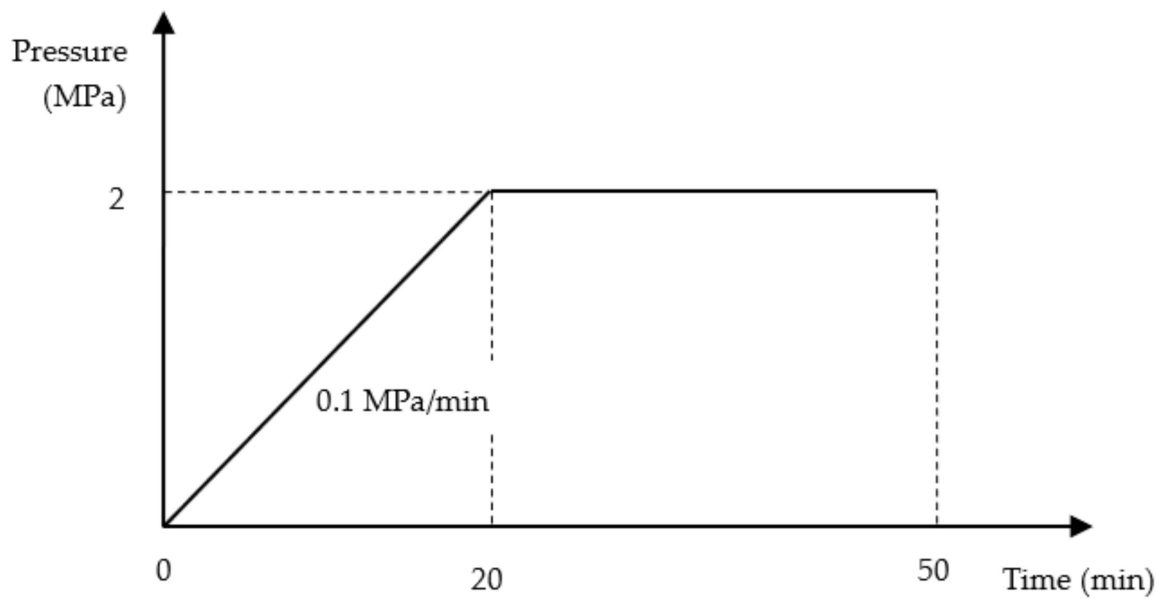

Figure 5. Curve of gas pressure on superplastic forming.

\section{Results and Discussion}

\subsection{The Two-Sheet Hollow Structure of 1420 Al-Li Alloy}

Figure 6 shows the two-sheet hollow structure of 1420 Al-Li manufactured by SPF/DB. It can be seen that the hollow structure was integrated, the surface was smooth, and there were no shape defects such as pit, wrinkle, and collapse. There was almost no clearance between the structure surface and the molds, and the structure shape was almost completely die-attached. In addition, there were no stomachs and inclusions on the diffusion bonding area and no wrinkles and adhesion on the superplastic forming area, as shown in Figure 7, which means good diffusion bonding quality between the two sheets and good superplastic forming. It also means that the two-sheet hollow structure of the 1420 Al-Li alloy was prepared successfully, with the diffusion bonding parameters of gallium interlayer thickness $1 \mathrm{mg} / \mathrm{cm}^{2}$, temperature $520^{\circ} \mathrm{C}$, pressure $7 \mathrm{MPa}$, and time $1 \mathrm{~h}$, and the superplastic forming parameters of temperature $480{ }^{\circ} \mathrm{C}$ and pressure $2 \mathrm{MPa}$ for $50 \mathrm{~min}$ by applying a speed of $0.1 \mathrm{MPa} / \mathrm{min}$. 


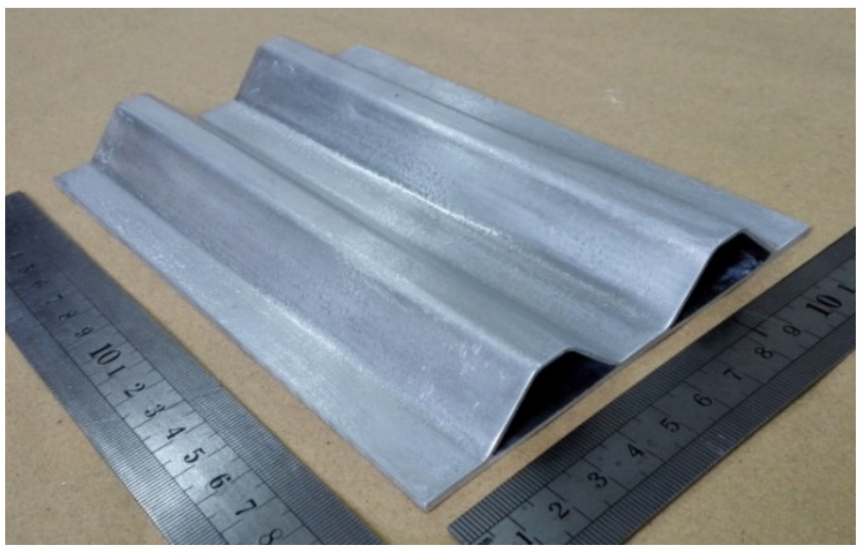

Figure 6. Two-sheet hollow structure of the 1420 Al-Li alloy.

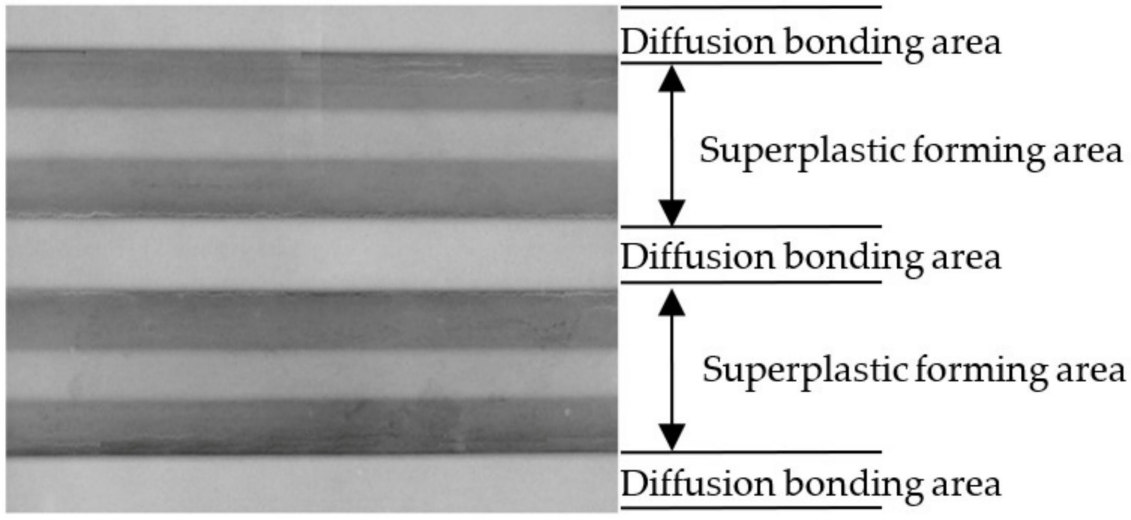

Figure 7. Defect detection by X-ray nondestructive inspection.

\subsection{The Microstructure of the Two-Sheet Hollow Structure of 1420 Al-Li Alloy}

The microstructure of the $1420 \mathrm{Al}-\mathrm{Li}$ alloy seriously influences the mechanical properties of the two-sheet hollow structure. Figure 8 shows the microstructure of the sample, where there is a dark area near the interface of the diffusion bonding area because of the existence of Ga. From Figure 8, it can be seen that the grain of the sheet's central layer was larger than that of the sheet's surface layer, which is caused by the previous sheet rolling process. During the rolling process, the surface temperature was transferred to the die and air, so the central temperature of the sheet was higher than the surface temperature, the surface softening degree was lower than the central softening degree, and there were many deformation energy and deformation defects in the surface layer. In addition, during the rolling process, the friction between the surface layer and the roll makes the surface bear great shear strain, and the deformation of the surface layer was greater than that of the central layer. The microstructure of the no deforming area is still a long strip, rolled microstructure (Figure 8b). Its grain size was larger than that of the original grain (Figure 1). The reason is that the grain grows through grain boundary migration under the conditions of high temperature and low strain rate deformation. Although there is a coordination effect of recrystallization, the grain always grows gradually at high temperatures. It is noted that grain boundary sliding is the main superplastic deformation mechanism of the $1420 \mathrm{Al} \mathrm{Li}$ alloy [18]. The grains near the round corner area are equiaxed states (Figure 8c). The reason for this is that superplastic deformation occurred at $480^{\circ} \mathrm{C}$ above the recrystallization temperature of the $\mathrm{Al}-\mathrm{Li}$ alloy, the dynamic recrystallization process of the $\mathrm{Al}-\mathrm{Li}$ alloy occurred, and fine equiaxed crystals were formed during the superplastic forming process [19-21]. Moreover, there were fine equiaxed grains at the triangular grain boundary (Figure 8c), which also demonstrated that the dynamic recrystallization process occurred in the process of superplastic deformation, which not only refined the grain structure, but 
also relieved the accumulation of dislocations and reduced the dislocation density, which is conducive to the superplastic forming process. It also proves that in the round corner area, the superplastic deformation mechanism of the $1420 \mathrm{Al} \mathrm{Li}$ alloy is mainly grain boundary sliding, accompanied by dynamic recrystallization [18].

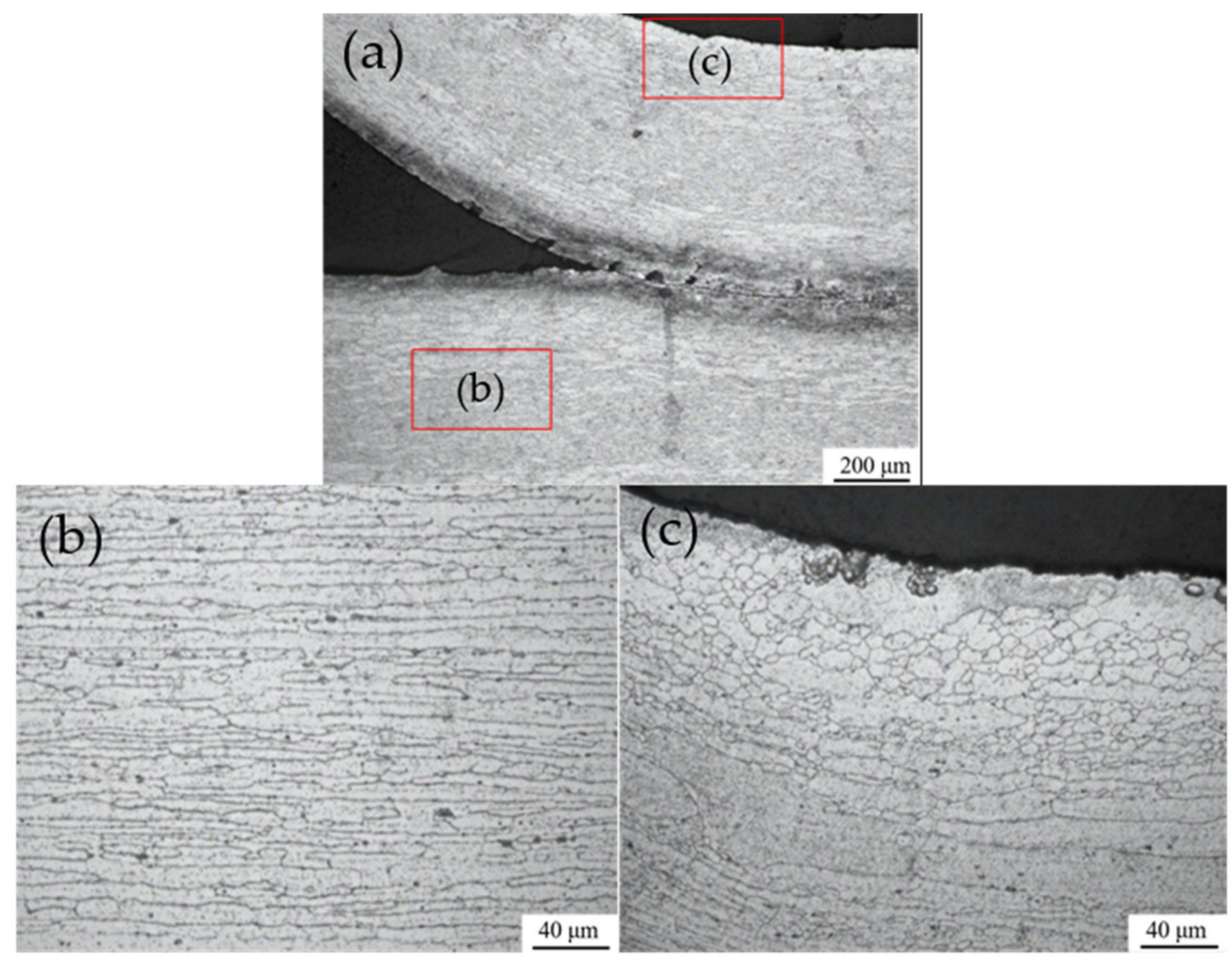

Figure 8. Microstructure of the sample: (a) the overall microstructure of the sample, (b) the no deforming area, (c) the round corner area.

The measured shear strength of diffusion bonding was about $82 \mathrm{MPa}$ (Figure 9), which is close to the value reported by Niu [17]. Figure 10 shows the shear fracture morphology of diffusion bonding. There were many coarse tear bands on the surface of the shear fracture, indicating that it is a ductile fracture. It was also demonstrated that the joint interface has achieved good metallurgical bonding.

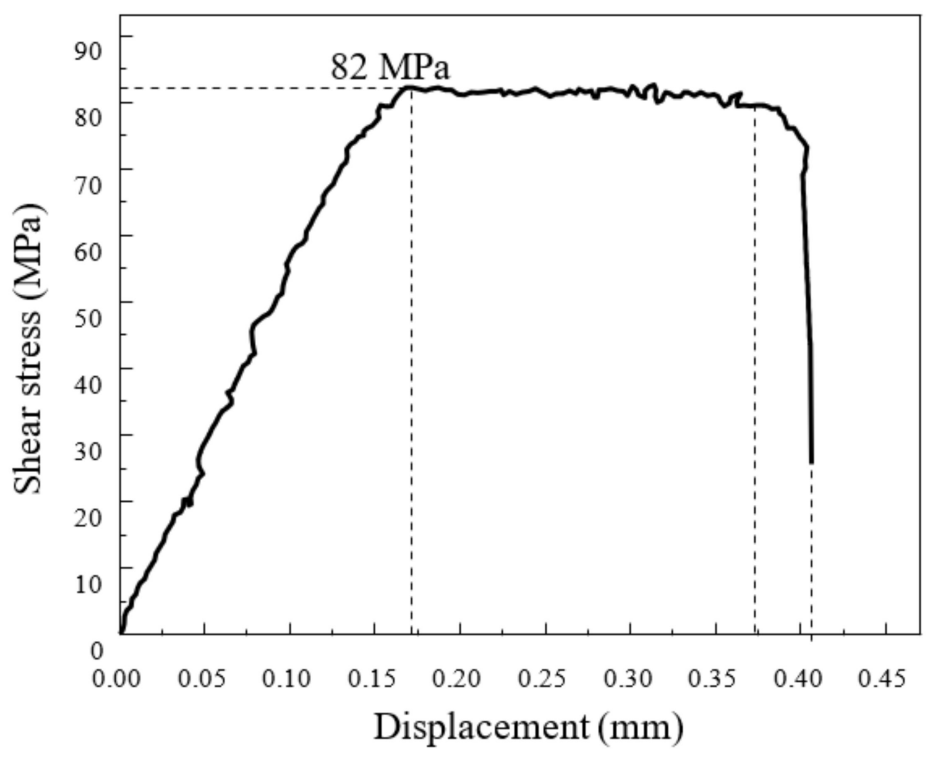

Figure 9. The shear stress-displacement curve of the shearing test. 


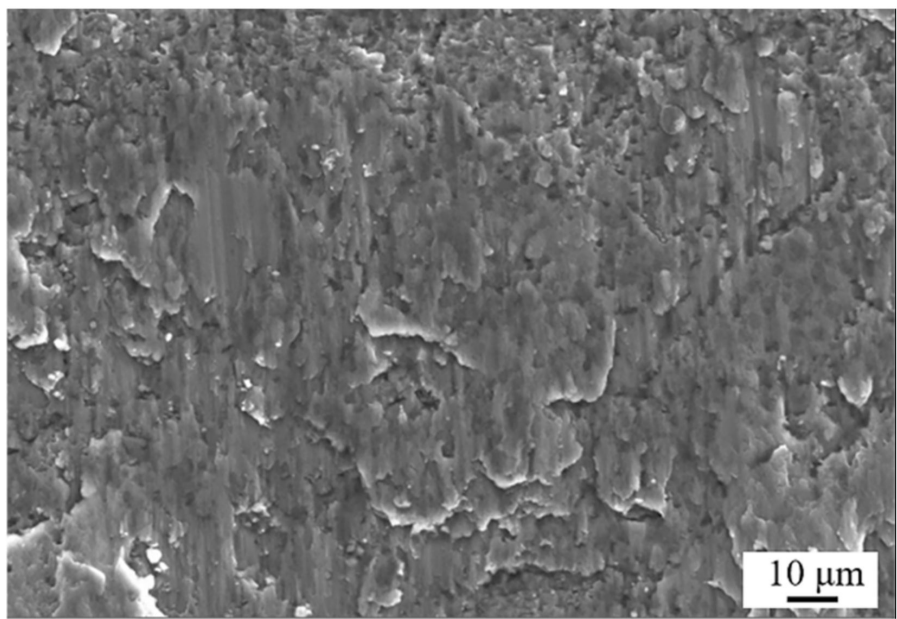

Figure 10. The shear fracture morphology of the shearing test.

\subsection{The Thickness Distribution of the Hollow Structure of 1420 Al-Li Alloy}

Thickness uniformity is an important factor which seriously influences the mechanical properties of the two-sheet hollow structure of 1420 Al-Li. Figure 11 shows the thickness distribution of the superplastic forming area measured by an ultrasonic thickness meter machine. The thicknesses of Points 3 and 9 were 1.29 and $1.30 \mathrm{~mm}$, respectively, which are close or equal to the initial thickness of $1.30 \mathrm{~mm}$. The thicknesses of Points 4, 5, 6, 7 , and 8 were $1.22,1.20,1.21,1.20$, and $1.21 \mathrm{~mm}$, respectively. It can be seen that the thickness change of the superplastic forming area was relatively uniform, there was no sudden change, and the maximum thickness reduction rate reached $7.7 \%$, which means good superplastic forming quality.

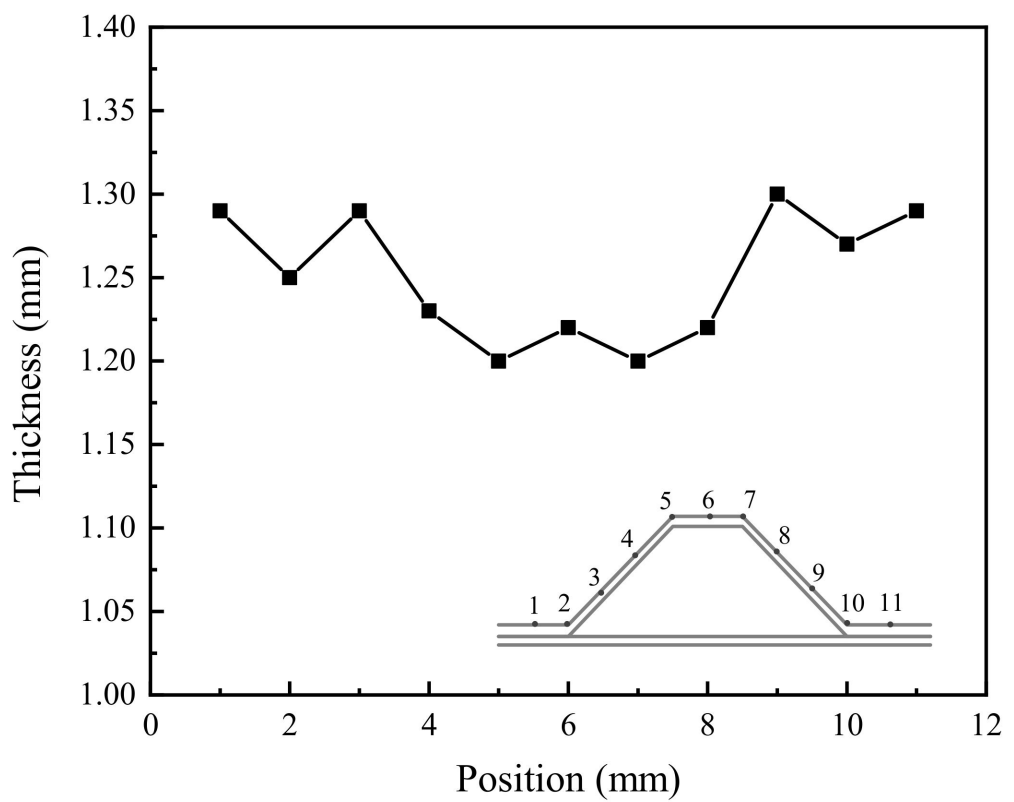

Figure 11. The thickness distributions.

\subsection{The Failure Mode of the Two-Sheet Hollow Structure of 1420 Al-Li Alloy}

From Figure 11, it can be obtained that the thicknesses of Points 2 and 10 were less than the thickness of the surrounding area, such as in Points 1, 3, 9, and 10, which was caused by the stress concentration on the inner surface near the round corner. It is noted that the inner surface near the round corner was also the most prone to tear, as shown in Figure 12. When the gas pressure of the superplastic forming process is too high or too 
fast, the sheet metal would deform quickly on the die cavity, and this results in a lower thickness (Points 2 and 10), local necking, and tearing at the round corner of the forming area, as shown in Figure 13. In addition, the supersaturated vacancies' accumulation also forms some holes. If the gas pressure remains too high, the tearing will continue until complete dehiscence and leakage. Therefore, the proper control of the gas pressure of the superplastic forming process is very important.

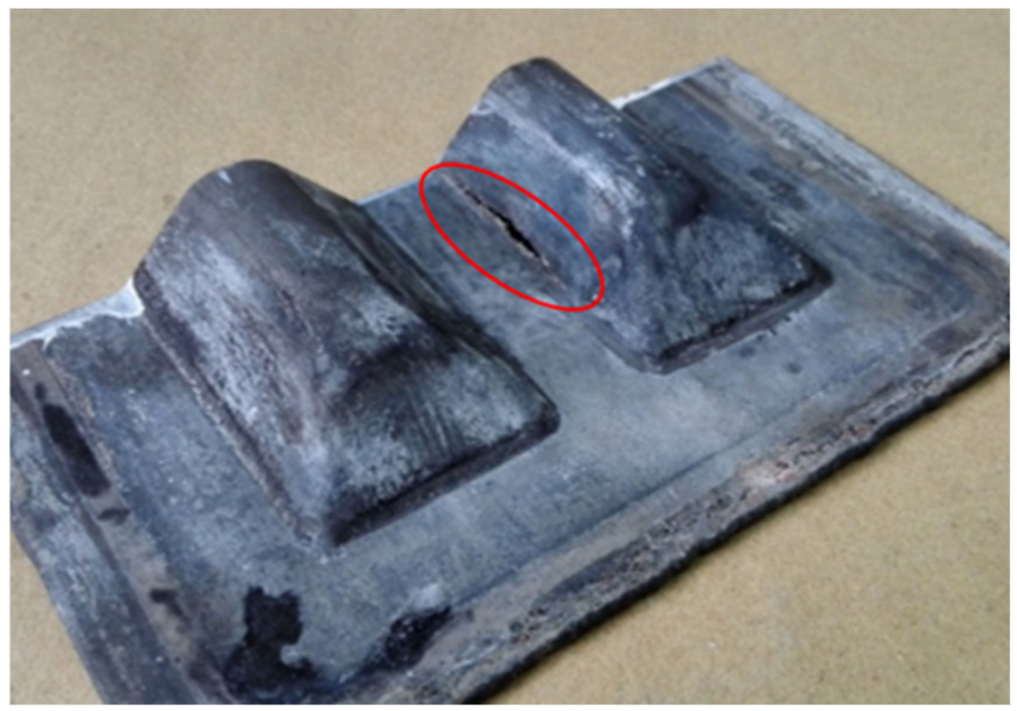

Figure 12. The tearing near the round corner of the forming area.

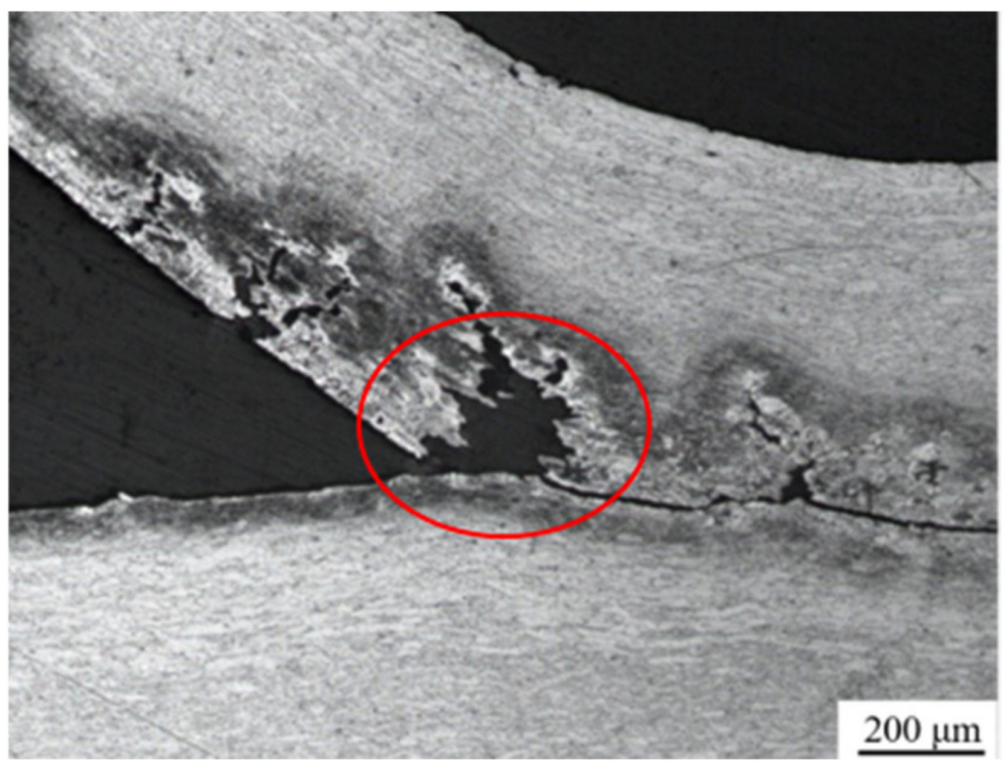

Figure 13. Tearing process on the inner surface near the round corner.

On the other hand, when the gas pressure of the superplastic forming process is too low, the sheet metal is not fully attached to the die cavity, which results in the die-attaching failure of the sample, as shown in Figure 14. In addition, when a leakage occurs in the seal welding process of the $1420 \mathrm{Al}-\mathrm{Li}$ hollow structure, this also results in the shortage of argon gas pressure in the forming process, and the shortage of forming pressure results in the die-attaching failure. Therefore, both the low gas pressure of the superplastic forming process and the leakage in the seal welding process result in the die-attaching failure of the sample. 


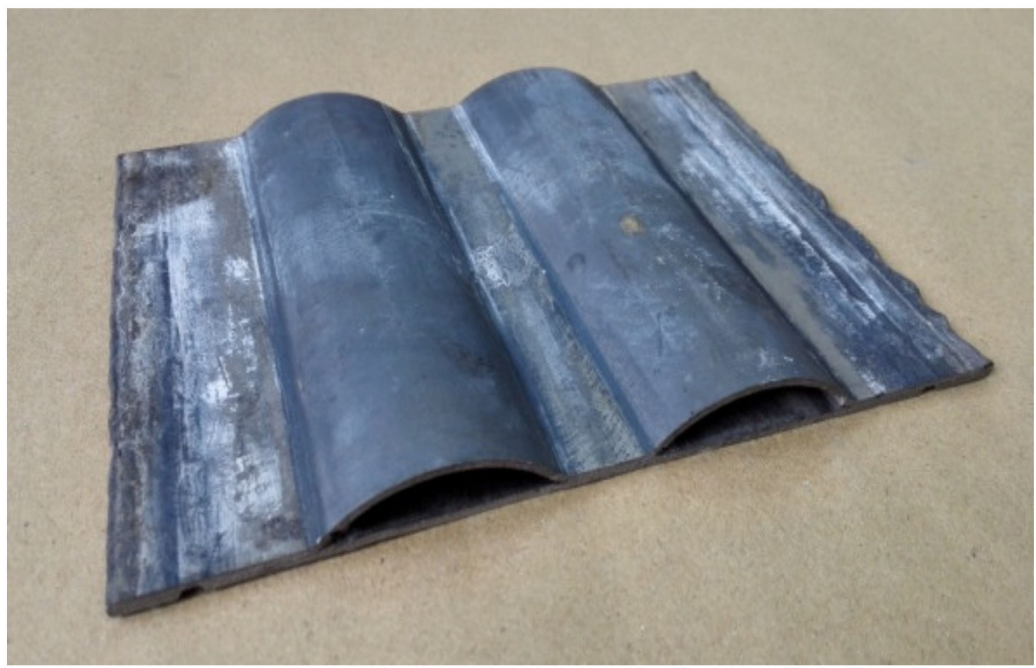

Figure 14. The die-attaching failure.

\section{Conclusions}

The two-sheet hollow structure of the $1420 \mathrm{Al}-\mathrm{Li}$ alloy is a typical structure urgently needed by flying weapon equipment, and SPF/DB is a special forming method with almost no allowance, low cost, and high efficiency. In this paper, the two-sheet hollow structure of the 1420 Al-Li alloy was prepared by the SPF/DB process, and the microstructure, the thickness distribution, and the superplastic forming failure modes were studied. The detailed conclusions are as follows:

1. The two-sheet hollow structure of the 1420 Al-Li alloy was successfully prepared with the diffusion bonding parameters of gallium interlayer thickness $1 \mathrm{mg} / \mathrm{cm}^{2}$, temperature $520{ }^{\circ} \mathrm{C}$, pressure $7 \mathrm{MPa}$, and time $1 \mathrm{~h}$, and the superplastic forming parameters of temperature $480^{\circ} \mathrm{C}$ and pressure $2 \mathrm{MPa}$ for $50 \mathrm{~min}$ by applying a speed of $0.1 \mathrm{MPa} / \mathrm{min}$.

2. Thickness uniformity is an important factor for the 1420 Al-Li hollow structure. When the gas pressure of the superplastic forming process was equal to $2 \mathrm{MPa}$, the thickness of the plastic deformation region was relatively uniform, there was no sudden change, and the maximum thickness reduction rate reached $7.7 \%$, which means good superplastic forming quality.

3. The no deforming area microstructure of the $1420 \mathrm{Al}-\mathrm{Li}$ hollow structure is still a long strip, rolled structure, while the grains near the round corner area of the $1420 \mathrm{Al}-\mathrm{Li}$ hollow structure were equiaxed states due to the dynamic recrystallization.

4. When the gas pressure of the superplastic forming process was too high, the lower thickness, local necking, and tearing occurred at the round corner of the sample due to excessive stress. When the gas pressure of the superplastic forming process was too low, the samples could not fully attach to the die cavity, and the die-attaching failure occurred.

Author Contributions: Methodology, writing-original draft preparation, supervision, Y.L. and H.W.; investigation, validation, T.N.; visualization, funding acquisition, H.Z.; conceptualization, project administration, writing-review and editing, M.Y. All authors have read and agreed to the published version of the manuscript.

Funding: The research was funded by the National Natural Science Foundation of China (51201155), Foundation of Equipment Pre-research Area (80923010401, 80923010403), Shanxi Province Science Foundation for Youths (201901D211203), and Shanxi Province Foundation for Returness (20200022 and 20210040).

Institutional Review Board Statement: Not applicable. 


\section{Informed Consent Statement: Not applicable.}

Data Availability Statement: The data are not publicly available. The data presented in this study are available from the corresponding author upon request.

Conflicts of Interest: The authors declare no conflict of interest.

\section{References}

1. Liu, X.; Ye, L.; Tang, J.; Dong, Y.; Ke, B. Superplastic deformation mechanism of an Al-Mg-Li alloy by high resolution surface studies. Mater. Lett. 2021, 301, 130251. [CrossRef]

2. Yuan, T.; Jiang, J.; Wang, L.; Ma, A.; University, H. Overview on the Microstructure and Mechanical Properties of Ultrafine-grained Al-Li Alloys Produced by Severe Plastic Deformation. Rare Met. Mater. Eng. 2019, 48, 55-62.

3. Li, S.; Huang, Z.; Jin, S. Superplastic Behavioral Characteristics of Fine-Grained 5A70 Aluminum Alloy. Met.-Open Access Metall. J. 2019, 9, 62. [CrossRef]

4. Li, S.; Jin, S.; Huang, Z. Cavity Behavior of Fine-Grained 5A70 Aluminum Alloy during Superplastic Formation. Metals 2018, 8, 1065. [CrossRef]

5. Liu, X.; Ye, L.; Tang, J.; Shan, Z.; Ke, B.; Dong, Y.; Chen, J. Superplastic deformation mechanisms of an Al-Mg-Li alloy with banded microstructures. Mater. Sci. Eng. A 2020, 805, 140545. [CrossRef]

6. Jia, L.; Ren, X.; Hou, H.; Zhang, Y. Microstructural evolution and superplastic deformation mechanisms of as-rolled 2A97 alloy at low-temperature. Mater. Sci. Eng. A 2019, 759, 19-29. [CrossRef]

7. Zhang, Y.L.; Qi, X.T. The experimental research on superplastic performance of fine-grained 1420 Al-Li alloy. J. Plast. Eng. 2009, 16, 134-137.

8. Barnes, A.J. Superplastic Forming 40 Years and Still Growing. J. Mater. Eng. Perform. 2007, 16, 440-454. [CrossRef]

9. Shirzadi, A.A.; Wallach, E.R. Novel Method for Diffusion Bonding Superalloys and Aluminium Alloys. U.S. Patent 6,669,534 B2, European Patent Pending. Mater. Sci. Forum 2005, 502, 431-436. [CrossRef]

10. Shirzadi, A.A.; Saindrenan, G. New Method for Flux Free Diffusion Brazing of Aluminium Alloys Using Liquid Gallium. UK Patent Application 0128623.6. Sci. Technol. Weld. Join. 2003, 8, 149-153. [CrossRef]

11. Ghoshouni, A.; Wallach, E.R. Surface Treatment of Oxidizing Materials. U.S. Patent 6,669,534 B2, 30 December 2003.

12. Shirzadi, A.A.; Saindrenan, G.; Wallach, E.R. Flux-Free Diffusion Brazing of Aluminium-Based Materials Using Gallium. UK Patent Application UK 0128623.6, 30 July 2002.

13. Shirzadi, A.A.; Assadi, H.; Wallach, E.R. Interface evolution and bond strength when diffusion bonding materials with stable oxide films. Surf. Interface Anal. 2001, 31, 609-618. [CrossRef]

14. Ferchaud, E.; Christien, F.; Barnier, V.; Paillard, P. Characterisation of Ga-coated and Ga-brazed aluminium. Mater. Charact. 2012, 67, 17-26. [CrossRef]

15. Niu, T.; Hou, H.; Wang, Y.; Zhou, W.; Fan, W.U. Effect of high uniform magnetic field on joining property and element diffusion of 1420 Al-Li Alloy. Trans. China Weld. Inst. 2016, 37, 1-5.

16. Niu, T.; Hou, H.L.; Wang, Y.Q.; Zhang, Y.L. Method and Technology of Diffusion Bonding of 1420 Al-Li Alloy by Using Gallium as Interlayer. Aeronaut. Manuf. Technol. 2015, 48, 0055-0062.

17. Niu, T.; Hou, H.L.; Wang, Y.Q.; Zhang, Y.L. Interfacial microstructure and mechanical property of diffusion bonding joint of 1420 Al-Li alloy by using gallium as interlayer. J. Plast. Eng. 2014, 21, 112-116.

18. Zheng, L.; Zhang, Y.; Wang, Y.; Hou, H.; Fan, T. Superplastic behavior of 1420Al-Li alloy. J. Shandong Univ. Eng. Sci. 2014, 44, 90-94.

19. Xin-Ming, Z.; Da-Wei, Z.; Ling-Ying, Y.E.; Jian-Guo, T. Superplastic deformation behavior and mechanism of 1420 Al-Li alloy sheets with elongated grains. J. Cent. South Univ. Technol. 2010, 17, 659-665.

20. Qing, L.; Xiaoxu, H.; Mei, Y.; Jinfeng, Y. On deformation-induced continuous recrystallization in a superplastic Al-Li-Cu-Mg-Zr alloy. Acta Metall. Mater. 1992, 40, 1753-1762. [CrossRef]

21. Shakesheff, A.J.; Partridge, P.G. Superplastic deformation of Al-Li-Cu-Mg alloy sheet. J. Mater. Sci. 1986, 21, 1368-1376. [CrossRef] 